\title{
Expressões da desigualdade social no Distrito Federal entre 2018 e 2020: O acirramento da "questão social" durante a pandemia da COVID-19
}

\author{
Expressions of social inequality in the Federal District between 2018 and 2020: The intensification \\ of the "social issue" during the COVID-19 pandemic \\ Expresiones de desigualdad social en el Distrito Federal entre 2018 y 2020: La intensificación del \\ "cuestión social" durante la pandemia COVID-19
}

Recebido: 12/04/2021 | Revisado: 19/04/2021 | Aceito: 21/04/2021 | Publicado: 07/05/2021

\author{
Michelly Ferreira Monteiro Elias \\ ORCID: https://orcid.org/0000-0002-9163-445X \\ Universidade de Brasília, Brasil \\ E-mail: michellyelias@unb.br
}

\begin{abstract}
Resumo
Este artigo apresenta resultados preliminares da pesquisa sobre as expressões da desigualdade social no Distrito Federal (DF) tendo como referência alguns dos principais dados socioeconômicos dessa realidade entre os anos de 2018 e 2020. Considera-se que o conjunto das desigualdades existentes na sociedade tem como fundamento a relação de exploração do capital sobre o trabalho, regida pela lei geral de acumulação capitalista, conforme desenvolvido por Marx no capítulo 23 do Livro 1 do Volume 1 da obra O Capital. A realização desse estudo baseia-se no método materialismo histórico dialético, utilizando procedimentos metodológicos de caráter quanti-qualitativo. Os estudos preliminares constatam a existência de uma profunda desigualdade socioeconômica no Distrito Federal (DF), identificando que as regiões administrativas que possuem a menor renda do PIB per capita possuem os maiores índices de desemprego e de trabalho informal, situação que tem se agravado durante a pandemia da COVID-19 e levado ao acirramento das expressões da "questão social", principalmente no que diz respeito ao aumento da pobreza, do desemprego e da desigualdade.
\end{abstract}

Palavras-chave: Questão social; Pandemia; Desigualdade.

\begin{abstract}
This article presents preliminary results of the research on the expressions of social inequality in the Federal District (DF) with as reference some of the main socioeconomic data of this reality between the years 2018 and 2020. It is considered that the set of inequalities existing in society is based on the relationship of exploitation of capital over work, governed by the general law of capitalist accumulation, as developed by Marx in chapter 23 of Book 1 of Volume 1 of the work $\mathrm{O}$ Capital. The performance of this study is based on the dialectical historical materialism method, using methodological procedures of quantitative-qualitative character. Preliminary studies show the existence of a deep socioeconomic inequality in the Federal District (DF), identifying that the administrative regions that have the lowest income of GDP per capita have the highest unemployment and informal labor rates, a situation that has worsened during the COVID-19 pandemic and ed to the intensification of the expressions of the "social issue", especially with regard to the increase in poverty, unemployment and inequality.
\end{abstract}

Keywords: Social issue; Pandemic; Inequality.

\section{Resumen}

Este artículo presenta resultados preliminares de la investigación sobre las expresiones de desigualdad social en el Distrito Federal (DF) con como referencia algunos de los principales datos socioeconómicos de esta realidad entre los años 2018 y 2020 . Se considera que el conjunto de desigualdades existentes en la sociedad se basa en la relación de explotación del capital sobre el trabajo, regido por la ley general de acumulación capitalista, desarrollado por Marx en el capítulo 23 del Libro 1 del Volumen 1 de la obra O Capital. La realización de este estudio se basa en el método de materialismo histórico dialéctico, utilizando procedimientos metodológicos de carácter cuantitativo-cualitativo. Estudios preliminares muestran la existencia de una profunda desigualdad socioeconómica en el Distrito Federal (DF), identificando que las regiones administrativas que tienen el ingreso más bajo del PIB per cápita tienen los mayores índices de desempleo y mano de obra informal, situación que ha empeorado durante la pandemia covid-19 y condujo a la intensificación de las expresiones de la "cuestión social", especialmente en lo que respecta al aumento de la pobreza, el desempleo y la desigualdad.

Palabras clave: Cuestión social; Pandemia; Desigualdad. 


\section{Introdução}

Esse artigo traz resultados preliminares sobre a pesquisa ${ }^{1}$ que vem sendo realizada em relação às expressões da desigualdade social no Distrito Federal (DF) no contexto anterior e atual da pandemia da COVID-19, tendo como referência alguns dos principais dados socioeconômicos dessa realidade entre os anos de 2018 e 2020.

A referida pesquisa está em andamento e os resultados preliminares aqui apresentados possuem um caráter introdutório, principalmente quando se considera a densidade da temática que esse estudo envolve no sentido de buscar identificar e entender as expressões da desigualdade social no Distrito Federal de maneira relacionada com o contexto da realidade brasileira.

Para essa abordagem parte-se da concepção que o conjunto das desigualdades existentes na sociedade tem como fundamento a relação de exploração do capital sobre o trabalho que é regida pela lei geral de acumulação capitalista.

Conforme Marx (1988) essa lei se constitui na necessidade de acumulação e reprodução do capital que se efetiva por meio da exploração da força de trabalho, de maneira que a produção de mais-valia é a lei absoluta desse modo de produção, onde o trabalho - produtor de mais-valia e tido como uma mercadoria qualquer do sistema produtivo - adquire utilidade somente quando é vendido ao capitalista, ou seja, somente quando estabelece uma relação de antagonismo e interdependência com o capital.

Desta maneira, a principal expressão dessa relação de exploração do capital sobre o trabalho para a geração de maisvalia enquanto fundamento da sua lógica de acumulação, está no fato de que toda riqueza apropriada pelo capital aumenta na mesma medida em que se aumenta a exploração da força de trabalho e se aprofunda a piora nas condições de vida dos (as) trabalhadores (as), estabelecendo a partir disso o cerne da "questão social" existente na sociedade burguesa. (Netto, 2006).

Com isso, entende-se a "questão social" de maneira determinada pela forma de organização das relações sociais da sociedade burguesa e definida enquanto "expressão das desigualdades sociais oriundas do modo de produção capitalista". (Santos, 2021, p. 17). Sendo que a partir do tempo histórico e do contexto social, econômico e político em que são situadas, as manifestações da "questão social" se materializam de múltiplas maneiras, seja através da pobreza, do desemprego, da violência, da exclusão e da banalização do humano. (Iamamoto, 2010).

Considerando essa concepção, esse artigo trata das principais características que permeiam as manifestações da "questão social" no âmbito da realidade brasileira no contexto histórico da hegemonia neoliberal, tendo como foco a atual conjuntura e as especificidades do Distrito Federal.

Para isso aponta-se alguns indicadores sobre o período de 2018 a 2020 e reflete-se sobre o aumento da desigualdade socioeconômica no Distrito Federal diante do atual quadro de crise social, econômica, política e sanitária vivenciada no Brasil.

\section{Metodologia}

Esse estudo baseia-se no método histórico-dialético que segundo Konder (2000) busca identificar as principais contradições que permeiam a questão pesquisada, apreendendo o movimento do real e visando a superação do fenômeno aparente enquanto fundamento da produção do conhecimento.

O método de investigação utilizado, entendido nessa perspectiva enquanto concepção de análise do fenômeno pesquisado, está baseado em três elementos fundamentais: “(1) minuciosa apropriação da matéria; (2) análise de cada forma de

\footnotetext{
1 Essa pesquisa está sendo realizada por inciativa da autora desse artigo que é professora adjunta do Departamento de Serviço Social da Universidade de Brasília (UnB), estudiosa de temas sobre questão social e lutas sociais na formação social brasileira e pesquisadora membro do Grupo de Estudos e Pesquisas Trabalho, Sociabilidade e Serviço Social (TRASSO). Essa pesquisa foi contemplada com o fomento previsto no Edital DPI/DPG N. 03/2020 - Apoio à execução de projetos de pesquisas científicas, tecnológicas e de inovação da Universidade de Brasília (UnB). Atualmente a pesquisa está na fase de coleta e sistematização de dados sobre a realidade socioeconômica do Distrito Federal (DF) e pretende ter continuidade até o período de finalização da pandemia da COVID-19.
} 
desenvolvimento do próprio material real; (3) investigação da coerência interna, isto é, determinação da unidade de várias formas de desenvolvimento". (Kosik, 1976, p. 37). Nesse sentido, ao se basear na análise do real por meio de sucessivas aproximações orientadas pela perspectiva teórico-metodológica do materialismo histórico-dialético, esse método buscará por meio de sucessivas aproximações apreender os fundamentos contraditórios que permeiam o fenômeno pesquisado, buscando identificar a relação de suas especificidades com a dimensão de totalidade do contexto social no qual está inserido.

O método buscará analisar as contradições enquanto dimensão do aspecto essencial da aparência, entendida enquanto dimensão fundante do real.

Com base nessa perspectiva, a pesquisa tem um caráter quanti-qualitativo, estando baseada em dados e indicadores numéricos sobre a realidade socioeconômica do Distrito Federal os quais serão analisados considerando "o universo dos significados, dos motivos, das aspirações, das crenças, dos valores e das atitudes [...] entendido aqui como parte da realidade social [...]". (Minayo, 2012, p. 21-22).

Os procedimentos metodológicos utilizados incluem a pesquisa bibliográfica, realizada através do levantamento e revisão de bibliografias sobre temas relacionados com a "questão social" na contemporaneidade brasileira e a pesquisa suplementar de dados, realizada através da consulta de indicadores socioeconômicos do Brasil e do Distrito Federal entre os anos de 2018 e 2020 nos bancos de dados do Instituto Brasileiro de Estatística e Geografia (IBGE) e da Companhia de Planejamento do Distrito Federal (CODEPLAN).

A partir do critério da amostragem e considerando que os indicadores socioeconômicos se constituem em dados estratégicos que propiciam melhor apreensão da realidade estudada, decidiu-se que os indicadores a serem analisados para conhecimento das expressões da desigualdade social no Distrito Federal entre 2018 e 2020 serão principalmente em torno do Produto Interno Bruto (PIB); da taxa de desemprego; da taxa do trabalho informal e da renda do PIB per capita por região administrativa.

\section{Resultados e Discussão}

\section{1 "Questão social" no contexto neoliberal da realidade brasileira}

No Brasil, o fenômeno da reestruturação produtiva, da ideologia neoliberal e da contra reforma do Estado a partir da década de 1990 até a atualidade constituiu uma realidade marcada pelo acirramento da "questão social", principalmente no que diz respeito à precarização das condições de vida e trabalho da classe trabalhadora, à perda de direitos sociais e ao aumento da desigualdade social.

De forma geral, o processo da reestruturação produtiva significou a implantação do padrão toyotista que flexibilizou a produção fordista e inseriu a produção de automação e descentralizada, levando à intensificação da terceirização e ocasionando o aumento de empregos temporários, da subcontratação, da desvalorização das normas salariais baseadas na Consolidação das Leis do Trabalho (CLT) e do aumento do desemprego, principalmente porque essas mudanças levaram à substituição de parte significativa da força de trabalho por sistemas de automação. Mecanismos que segundo Antunes (2010) proporcionaram maiores níveis de exploração da força de trabalho, possibilitando o aumento da extração de mais-valia por parte do capital. Além de reduzirem o operariado fabril e ampliarem o trabalho assalariado desregulamentado e informal em outros setores, como o de serviços. 
Esse processo, além de ocasionar uma piora nas condições de vida e trabalho para a maioria da população, ocasionou uma "maior heterogeneização, fragmentação e complexificação da classe trabalhadora" (Antunes, 2010, p. 47), impondo inúmeros desafios para a luta sindical ${ }^{2}$ a partir da década de 1990 frente ao contexto de perda de direitos sociais.

O modelo neoliberal nesse período redimensionou a atuação estatal frente às expressões da "questão social" no país, o que significou um retrocesso no âmbito das políticas sociais em que predominaram "ações pontuais e compensatórias direcionadas para os efeitos mais perversos da crise" (Behring; Boschetti, 2008, p. 156), aprofundando a fragilidade e a fragmentação dessas políticas.

Através dessas características, esse processo ocorreu no Brasil de maneira vinculada ao contexto internacional de reestruturação produtiva estabelecida desde a década de 1970 nos países de economia central, tendo seu início durante o Governo de Fernando Collor de Mello (1990-1992) e se consolidando durante o Governo de Fernando Henrique Cardoso (1995-2002).

Ambos os governos se caracterizaram por implementarem medidas de privatização dos serviços públicos e de ajuste fiscal que viabilizaram o avanço da acumulação financeira que beneficia principalmente o capital internacional de caráter monopólico. Sendo que essa forma de acumulação se baseia na dinâmica em que o capital-dinheiro é remunerado por meio dos juros proporcionando o crescimento do capital fictício, constituído principalmente pelo mercado de ações. (Chesnais, 1996).

Nesse sentido, a atuação estatal sob a perspectiva neoliberal implementou sob os moldes do capitalismo contemporâneo ações visando a liberalização do mercado e a expansão dos investimentos de capital privado no país, de maneira que grandes grupos empresariais, em particular os monopólios, passaram a exercer o comando da economia sob a lógica da acumulação financeira.

Dentre essas principais ações estatais, é possível citar a criação de mecanismos de garantia de segurança no cenário político; a expansão de subsídios e incentivos fiscais; a redução dos gastos públicos em políticas sociais; a reorientação do fundo público para o atendimento das demandas do capital privado.

Essa perspectiva de atuação passou a se expressar concretamente desde a adesão do Brasil às orientações do Consenso de Washington de 1989; com a privatização de empresas estatais como a Vale do Rio Doce em 1996; de empresas estratégicas na área de telecomunicações e com o aprofundamento do papel desempenhado pelo Brasil na divisão internacional do trabalho de exportador de matérias-primas, principalmente de monoculturas (soja, milho, eucalipto) que se tornaram commodities no mercado financeiro.

A partir desses elementos, vê-se que tanto do ponto de vista econômico, quanto do ponto de vista político e social, o processo de implantação do neoliberalismo no Brasil estabeleceu uma dinâmica que acelerou e aprofundou os níveis de desigualdade social na realidade brasileira, manifestados nos crescentes índices de desemprego, pobreza, baixa escolaridade e desregulamentação do trabalho, ao mesmo tempo em que a concentração da renda e da riqueza aumentou. Dados sistematizados por Santos (2012) demonstram que o Brasil chegou em 1998 com 19\% de desemprego, com 46,7\% das pessoas com ocupação em regime de trabalho não regulamentado ou em "trabalho autônomo". Enquanto os 10\% mais ricos em 1999 se apropriavam de $47,4 \%$ do total da renda nacional e os $50 \%$ mais pobres possuíam $12,6 \%$, de maneira que os $10 \%$ mais ricos chegavam a ter quase quatro vezes mais a renda dos $50 \%$ mais pobres.

De forma estrutural, essas principais determinações acerca da realidade brasileira na década de 1990 permaneceram na década de 2000, havendo a continuidade da predominância do capital financeiro enquanto principal forma de acumulação do

2 O contexto político dos anos de 1990 se caracterizou pela fragilidade do movimento sindical e diminuição da sua base social, perda de sua capacidade de pressão política junto às empresas e ao Estado, além de ter sido fortemente afetado por uma cultura individualista e despolitizada, imposta pela sociabilidade neoliberal. Um dos acontecimentos mais emblemáticos que expressaram a fragilização do movimento sindical durante esse período foi a derrota da greve dos petroleiros em 1995. 
capitalismo contemporâneo e da atuação do Estado para flexibilizar e viabilizar o desenvolvimento do capital sob essa perspectiva.

A partir desse contexto de hegemonia neoliberal os Governos do Partido dos Trabalhadores (PT) entre os anos de 2003 e 2016 se caracterizaram por algumas mudanças na política econômica que tinha se consolidado no período anterior, buscando desenvolver programas e medidas de incentivo à produção e à indústria nacional, a exemplo da criação do Programa de Aceleração do Crescimento (PAC) em 2007. Além de ter fortalecido e ampliado políticas sociais, como a política de assistência social através da regulamentação do Sistema Único de Assistência Social (SUAS) em 2003; a política de educação com a expansão do acesso ao ensino superior através do Programa Universidade para Todos (PROUNI) criado em 2004 e do Programa de Apoio a Planos de Reestruturação e Expansão das Universidades Federais (REUNI) criado em 2007; a política de habitação através da criação de programas sociais como o "Minha Casa Minha Vida" em 2009; a política de emprego e renda através da concessão de incentivos às empresas privadas para a criação de novos postos de trabalho e ao setor público através da ampliação dos concursos, além da criação da política permanente de reajuste do salário mínimo conforme os índices de inflação.

Por outro lado, viu-se nesse mesmo período que políticas públicas estruturantes como a reforma agrária pouco avançaram, ao mesmo tempo em que a concentração da riqueza e da renda manteve a sua base estrutural, conforme afirma Santos (2012).

Diante dessas contradições, mas considerando as diferenças na atuação do Governo Federal do Partido dos Trabalhadores (PT) em relação ao período neoliberal dos Governos de Fernando Henrique Cardoso (FHC), passou-se a desenvolver desde 2011 o debate sobre a existência de uma fase neodesenvolvimentista no Brasil associada a uma perspectiva de "neoliberalismo reformado" baseado na produção industrial do mercado interno, mas que não se propunha a romper definitivamente com a hegemonia neoliberal.

Com isso, autores como Boito Junior (2012) apontam que ao se considerar a atuação do Estado brasileiro através das ações do poder executivo nacional a partir dos anos 2000, pode-se afirmar que a conjuntura brasileira durante os governos do Partido dos Trabalhadores (PT) se caracterizou por políticas neodesenvolvimentistas ocorridas sob marcos neoliberais.

Nesta perspectiva, Almeida (2012) afirma que esses Governos não seguiram exatamente a ortodoxia neoliberal do período do Governo Fernando Henrique Cardoso (FHC), se diferenciando principalmente em relação à política econômica, em que utilizaram mecanismos de política fiscal, cambial e de crédito para incentivar a economia nacional, juntamente com a estratégia de ampliação das ações voltadas para os setores mais pauperizados da população. Ao mesmo tempo em que atuaram com vistas a ampliar as possibilidades de expansão da acumulação do capital, principalmente o de origem nacional.

Contudo, ao se considerar o histórico da formação social brasileira caracterizada pelo desenvolvimento de um capitalismo dependente ${ }^{3}$ e o contexto internacional de hegemonia neoliberal e do capital financeiro na contemporaneidade, aponta-se que a realização desse pacto que os Governos do Partido dos Trabalhadores (PT) conseguiram mediar entre 2003 e 2016, acabou gerando um conjunto de contradições e conflitos nas esferas econômicas e políticas que acirraram as disputas entre as classes sociais e seus segmentos. Processo que teve como principal consequência o golpe parlamentar, que com o apoio das classes dominantes suspendeu o mandato presidencial de Dilma Rousseff em 2016, e deu início ao Governo do então vice-presidente Michel Temer do Movimento Democrático Brasileiro (MDB) que governou o país até 2018.

Sendo assim, ao se estabelecer um Governo não eleito para comandar o Brasil enquanto tentativa de resolução da crise vivenciada pelo capital naquele contexto, o período entre 2016 e 2018 foi de retomada da ofensiva neoliberal de caráter

3 Nessa perspectiva, compreende-se que o capitalismo dependente se estabelece "como uma relação de subordinação entre nações formalmente independentes, em cujo marco as relações de produção das nações subordinadas são modificadas ou recriadas para as segurar a reprodução ampliada da dependência. A consequência da dependência não pode ser, portanto, nada mais do que maior dependência, e sua superação supõe necessariamente a supressão das relações de produção nela envolvida" (Marini, 2005, p. 141). 
ortodoxo, visando a ampliação acelerada dos mecanismos de maior exploração da força de trabalho. Fato que ao expressar a fragilidade do regime democrático no país e se associar ao fortalecimento do neoconservadorismo na sociedade brasileira, levou à eleição do Governo Bolsonaro em 2018.

\subsection{Acirramento da "questão social" na conjuntura brasileira atual}

Dentre os diversos aspectos acerca da realidade brasileira atual, aponta-se que juntamente com a crise sanitária causada pela pandemia da COVID-19, vive-se um contexto de profunda crise econômica e social que tende a se agravar diante da existência de um Governo Federal representante do neoconservadorismo, da ortodoxia neoliberal e do autoritarismo político.

Segundo dados do Instituto Brasileiro de Geografia e Estatística (IBGE), o Brasil teve em 2020 uma queda no Produto Interno Bruto (PIB) de 4,1\% e uma taxa de desemprego de 13,9\% da população economicamente ativa. Enquanto que ano anterior, o Relatório da Organização das Nações Unidas (ONU) divulgado no final de 2019 ao abordar dados sobre a distribuição de renda apontava que o $1 \%$ da população mais rica detinha $28,3 \%$ da renda do país, ou seja, quase um terço do total.

A partir desses indicadores, é possível perceber alguns dos principais efeitos da atual crise, que iniciada em $2013 \mathrm{e}$ aprofundada desde 2016, vem adquirindo proporções devastadoras no contexto da pandemia da COVID-19, principalmente no que diz respeito ao emprego, à desigualdade e à pobreza, juntamente com a perda de vidas que no atual momento chegou a mais de 4.000 óbitos diários.

Em relação à crise social, dados divulgados pela Agência Senado (2021) demonstram que mais de 30\% dos 211,8 milhões de brasileiros tiveram que ser atendidos pelo auxílio emergencial em 2020, enquanto única forma de terem acesso mínimo às suas necessidades de sobrevivência durante a pandemia.

Essa realidade, além de estar determinada pelo contexto internacional de crise do capital e pela hegemonia neoliberal na contemporaneidade, conforme já abordado anteriormente, demonstra que o acirramento das expressões da "questão social" na realidade brasileira também está determinado pelas especificidades da conjuntura atual.

Nesse sentido, destaca-se a configuração da política econômica que desde 2016 vem fortalecendo o papel desempenhado pelo Brasil na divisão internacional do trabalho de produtor e exportador de produtos agrícolas e minério e de pagador dos juros da dívida, ou seja, "de pagador de rendas à propriedade do capital, sobretudo do capital financeiro". (Paulani, 2019, p. 55). Aspectos que aprofundam a condição de dependência da economia brasileira através da exportação de bens com baixo valor agregado e de perda de autonomia por parte do Estado em relação ao seu próprio orçamento, que passa a ser cada vez mais gerido conforme as necessidades e interesses do capital financeiro portador de juros.

Associado a isso, ressalta-se que o atual Governo brasileiro tem atuado pela implantação de uma agenda econômica de caráter ultraneoliberal que prevê a ampliação das contrarreformas que desregulamentam direitos trabalhistas e previdenciários. Além da realização de medidas de ajuste fiscal que ao diminuírem o financiamento público destinado a políticas sociais como saúde e educação, visam acelerar o seu processo de privatização.

Desta maneira, sob a égide ultraneoliberal associada ao discurso nacionalista reacionário, o atual Governo visa implantar a qualquer custo,

[...] uma agenda econômica centrada na imposição de um ajuste fiscal draconiano; na financeirização da previdência e da educação; na universalização da mercantilização de serviços e bens até então (integral ou parcialmente) estatais; na exploração criminosa e predatória de recursos naturais e em um cruel rebaixamento das condições salariais da força de trabalho como forma de elevar a taxa de lucros e atender aos interesses do capital financeiro e rentista (Mota e Rodrigues, 2020, p. 204) 
Dentre as diversas consequências dessa política econômica ultraneoliberal, aponta-se o aumento significativo da concentração de renda juntamente com a precarização do trabalho e a piora nas condições de vida da maioria da população, que durante a pandemia da COVID-19 vem adquirindo níveis de tragédia social.

Nesse contexto, percebe-se em relação aos processos de trabalho uma realidade caracterizada pelo aumento de postos de emprego sem nenhum tipo regulamentação; constante diminuição da média salarial dos trabalhadores (as); expansão dos regimes de trabalho intermitentes; enfraquecimento dos sindicatos e aumento escalonado do desemprego, levando milhares de pessoas à condição de vulnerabilidade socioeconômica.

Nessa perspectiva, os estudos de Pochmann (2020) indicam que no contexto de expansão neoliberal no Brasil entre 1989 e 2019, a taxa de assalariamento diminuiu em 6,7\% e o desemprego aumentou em 11\%. Enquanto que no universo da população ocupada, o emprego formal diminuiu em 14,8\%, a taxa dos não assalariados aumentou em $12 \%$, os postos de trabalho com rendimento acima de 5 salários mínimos diminuiu de 9,9\% para 8\% e a remuneração de até dois salários mínimos aumentou $3,8 \%$.

Dados que demonstram que o processo de precarização do trabalho no país não se constitui enquanto fenômeno específico da atual conjuntura, mas que, em simultâneo, apontam que diante do atual quadro de crise vivenciada durante a pandemia da COVID-19, a perspectiva é de que essa situação se agrave severamente.

Principalmente quando se reconhece hoje no Brasil a existência de uma dinâmica de avanço do neoconservadorismo que dentre outros aspectos, se apresenta enquanto uma forma de enfrentamento das problemáticas colocadas pela realidade brasileira atual por parte do atual Governo Federal.

Considerando o contexto geral de avanço do neoconservadorismo na sociedade burguesa contemporânea, Almeida (2018) afirma que o neoconservadorismo entende que as crises vivenciadas pela sociedade desde o final da década de 1960 e início dos anos de 1970 dizem respeito a "uma crise moral, ocasionada pelo abandono dos valores tradicionais que governam a sociedade desde os primórdios da civilização, feito em nome de um igualitarismo artificialmente criado pela intervenção estatal". (Almeida, 2018, p. 28).

Desta maneira, o neoconservadorismo entende que o Estado de Bem-Estar Social, estabelecido entre 1945 e 1970 de maneira diferenciada nos países da Europa Ocidental, foi o principal causador das sucessivas crises vivenciadas pela sociedade burguesa desde aquele período até os dias atuais. Compreendendo assim que a política do pleno emprego, a expansão dos direitos de cidadania e a atuação do Estado como principal mediador da acumulação econômica, originaram a crise existente.

Sendo assim, identifica-se que ao explicar desta maneira a crise estrutural do capital existente desde a década de 1970, o neoconservadorismo demonstra uma profunda crítica ao intervencionismo estatal na economia e à regulamentação dos direitos de cidadania, em particular em relação aos direitos sociais.

Essa constatação revela a profícua relação estabelecida no contexto histórico atual entre as ideias neoconservadoras e o neoliberalismo, que embora possam parecer divergentes em um primeiro momento, são em essência complementares, a exemplo do que ocorre hoje em relação ao atual Governo brasileiro.

Nesse sentido, destaca-se que apesar das contradições e conflitos existentes hoje entre as próprias classes e segmentos que dirigiram o processo que levou Bolsonaro à Presidência da República em 2018, um aspecto geral que fundamenta a atuação desse Governo é o desenvolvimento de políticas de austeridade e ajuste fiscal, o ataque às liberdades democráticas e a disseminação do ódio e da intolerância às mulheres, às pessoas negras, aos indígenas, aos movimentos populares, às ideias progressistas e ao racionalismo, ou seja, é a associação da perspectiva econômica ultraneoliberal com o neoconservadorismo.

Situação que dentre os seus diversos desdobramentos tem determinado uma realidade de profunda crise, levando à restrição de parte significativa dos direitos de cidadania, em particular dos direitos sociais. Contribuindo desta maneira para o acirramento das expressões da "questão social" durante a pandemia da COVID-19. 


\section{3 "Questão social” e expressões da desigualdade social no Distrito Federal}

Enquanto parte dessa complexa realidade brasileira, o Distrito Federal (DF) é uma Unidade da Federação (UF) que segundo dados do IBGE (2020) possui uma população de 3.055 .149 pessoas residindo e trabalhando em 33 regiões administrativas ${ }^{4}$.

Diante dos estudos preliminares realizados sobre as expressões da desigualdade social no DF no contexto anterior e atual da pandemia da COVID-19, parte-se de alguns dados gerais sobre essa realidade a partir de 2018, ano de início do atual Governo Federal.

Dados da pesquisa realizada pelo IBGE em 2018 e divulgados em 2020, demonstram que o DF teve nesse ano um Produto Interno Bruto (PIB) no valor total de R \$254,817 bilhões, sendo o oitavo maior PIB do país. Contudo, conforme dados divulgados pela CODEPLAN (2020), ao possuir um PIB per capita de $\mathrm{R} \$ 85.661,39$, o DF passa a ocupar o primeiro lugar do País, tendo além do maior PIB per capita da Federação um total equivalente a 2,5 do PIB per capita do Brasil que é de R\$ 33.594,00. Para a geração desse PIB, o DF possui enquanto principais atividades e setores econômicos, o setor de serviços responsável por $50,3 \%$, a administração pública responsável por $45 \%$, a indústria responsável por $4,2 \%$ e a agropecuária responsável por $0,5 \%$.

Junto a isso, destaca-se enquanto particularidade do DF, a significativa distribuição desigual da renda desse PIB per capita por região administrativa. Como exemplo disso, os dados da CODEPLAN (2020a) demonstram que as regiões administrativas do SCIA/Estrutural e Varjão possuem o PIB per capita mais baixo da Unidade Federativa, sendo de até R\$ 500,00 , enquanto o Lago Sul possui o mais alto no valor de $\mathrm{R} \$ 7.000,00$ a $\mathrm{R} \$ 8.000,00^{5}$.

Em relação ao trabalho e rendimento o Distrito Federal possuía no período de realização da última pesquisa do IBGE, em 2018, uma média salarial por trabalhador (a) formal de 5,5 salários mínimos por mês, tendo a $5^{\text {a }}$ maior média salarial do país. Ao mesmo tempo, possuía $45,5 \%$ da sua população total desenvolvendo alguma atividade laboral com remuneração e apresentava 30,9\% dos domicílios com renda per capita de até $1 \frac{1}{2}$ salário por pessoa. (IBGE, 2020).

Sobre o acesso à política de educação, o IBGE (2020) identificou que 97,5\% da população possui algum nível de escolaridade, e em relação à infraestrutura se constatou na mesma pesquisa que $87,9 \%$ da população tem acesso ao esgotamento sanitário adequado. Dados que são importantes para o conhecimento da realidade socioeconômica do DF, uma vez que dizem respeito às condições de vida e de acesso a bens e serviços por parte da população e que não se alteram rapidamente a partir de conjunturas específicas, possuindo um caráter mais estruturante enquanto políticas e serviços públicos.

Em relação ao mesmo período de 2018, os dados sobre emprego demonstram que neste ano houve no DF uma taxa de desemprego de 18,6\% da população economicamente ativa, tendo um índice mais alto de 22,1\% nas regiões administrativas de Brazlândia, Ceilândia, Planaltina, Riacho Fundo, Riacho Fundo II, SIA, Samambaia, Santa Maria e São Sebastião. Seguido a isso, no ano de 2019 o desemprego chegou a 18,3\% em todo o DF, tendo um índice mais alto de $24,6 \%$ nas regiões administrativas de Fercal, Itapoã, Paranoá, Recanto das Emas, SCIA/Estrutural e Varjão. (CODEPLAN, 2021).

4 Águas Claras, Arniqueira, Brazlândia, Candangolândia, Ceilândia, Cruzeiro, Fercal, Gama, Guará, Itapoã, Jardim Botânico, Lago Norte, Lago Sul, Núcleo bandeirante, Paranoá, Park Way, Planaltina, Plano Piloto, Recanto das Emas, Riacho Fundo, Riacho Fundo II, Samambaia, Santa Maria, São Sebastião, SCIA/Estrutural, SIA, Sobradinho, Sobradinho II, Sol Nascente/Pôr do Sol, Sudoeste/Octogonal, Taguatinga, Varjão, Vicente Pires.

5 Com base nos dados da CODEPLAN (2020a), a síntese geral da distribuição da renda per capita do PIB por região administrativa do DF é: Renda até R\$ 500,00 (SCIA/Estrutural, Varjão); renda entre R \$ 500,00 e R\$ 1.000,00 (Planaltina, Paranoá, Ceilândia, Samambaia, Santa Maria, Recanto das Emas, Riacho Fundo II, Fercal, Itapoã); renda entre R\$1.000,00 e R\$2.000,00 (Candangolândia); renda entre R\$ 2000,00 a R\$ 3000,00 (Gama, Taguatinga, Brazlândia, São Sebastião, Sobradinho 2, Riacho Fundo, Vicente Pires), renda entre R\$ 3.000,00 a $\mathrm{R} \$ 4.000,00$ (Sobradinho, Núcleo Bandeirante, SAI), renda entre R \$ 4.000,00 a R \$ 5.000,00 (Park Way), renda entre R $\$ 5000,00$ a $R \$$ 6000,00 (Jd. Botânico, Sudoeste/Octogonal, Plano Piloto), renda entre R\$ 6.000,00 a R\$ 7.000,00 (Águas Claras, Lago Norte), renda entre $\mathrm{R} \$ 7.000,00$ a R \$ 8.000,00 (Lago Sul). As regiões administrativas de Arniqueira e Sol Nascente/Pôr do Sol não aparecem nessa pesquisa porque foram criadas em 2019 e esses dados foram coletados em 2018. 
Além do índice de desemprego, outro dado que é importante destacar é taxa de informalidade do trabalho no DF, que em 2018 foi de $28,74 \%$, tendo a região administrativa do Varjão a maior taxa de informalidade, chegando a 49,68\%. (CODEPLAN, 2020b).

Considerando esses dados, identifica-se que a partir 2020 a existência da pandemia da COVID-19 passou a intensificar os desafios acerca dessa realidade socioeconômica do DF, diante do agravamento da crise econômica, social, política e sanitária vivenciada no país.

Nesse sentido, destaca-se primeiramente que ainda são muito preliminares os dados divulgados sobre o DF no atual contexto de recrudescimento da pandemia da COVID-19. Principalmente porque a atual crise tem inclusive dificultado a realização de pesquisas de levantamento de dados.

Contudo, dentro do que foi possível identificar até o momento, aponta-se que a CODEPLAN ainda não divulgou o PIB de 2020. Porém, apresentou que durante o período de maior intensificação da pandemia durante o segundo trimestre desse ano, a economia teve uma variação negativa de $4,2 \%$ com queda de $-10,9 \%$ no setor industrial, $-3,9 \%$ no setor de serviços, $20 \%$ no setor do comércio, $-15,1 \%$ no setor de construção e um crescimento do setor agropecuário de 2,1\%. (CODEPLAN, 2021a)

Ainda nesse período a taxa de desemprego atingiu o índice de 21,6\% da população economicamente ativa, juntamente com uma diminuição de 7\% da renda dos (as) trabalhadores (as) formais. Contudo, ao se considerar todo o ano de 2020 o índice de desemprego se manteve na média geral de 18\% com um índice de 23\% nas regiões administrativas que possuem as menores rendas do PIB per capita. (CODEPLAN, 2021a).

Em relação ao trabalho informal, houve entre os meses de julho e setembro de 2020 um aumento de $11 \%$, em comparação com os meses anteriores do mesmo ano, conforme dados divulgados pelo IBGE (2020a), chegando nesse período a um índice de $28,6 \%$ da população economicamente ativa do DF.

Nesse sentido, aponta-se que esses dados acerca da economia e do trabalho no DF durante o ano de 2020 são os indicadores que foram possíveis de serem identificados até o momento e que ao ter continuidade, essa pesquisa pretende incorporar outros elementos dessa realidade para se tenha um melhor entendimento sobre como a "questão social" tem se acirrado no DF no contexto da pandemia da COVID-19.

\section{Considerações Finais}

Diante dos elementos abordados nesse artigo, aponta-se que o atual contexto de crise do capital se manifesta na realidade brasileira por meio do acirramento da "questão social". Processo que a partir da reestruturação produtiva e da implantação do neoliberalismo na década de 1990 aprofundou os níveis de desigualdade social historicamente presentes na formação social brasileira.

Nesse sentido, constata-se que o capitalismo dependente estabelecido no Brasil, vem se desenvolvendo desde a década de 1990 (apesar da existência de conjunturas diferenciadas em relação aos Governos Federais) sob a égide da hegemonia neoliberal, constituindo uma realidade caracterizada predominantemente pela restrição das políticas sociais, por mudanças no mundo do trabalho visando o aumento incessante da exploração da força de trabalho, pela expansão da acumulação financeira e por conjunturas políticas de fragilização do regime democrático.

Considerando essa herança, o atual quadro de crise econômica, social, política e sanitária, tem se agravado principalmente devido à atuação do atual Governo Brasileiro frente ao contexto da pandemia da COVID- 19. De maneira que, em relação à atual tragédia humanitária vivenciada pelo Brasil, ressalta-se a perda de 337.000 vidas até o momento no país e o aprofundamento da crise social através do aumento escalonado do desemprego, da pobreza e da desigualdade. 
Enquanto parte dessa realidade, o Distrito Federal (DF) se caracteriza pela especificidade de possuir a maior renda do PIB per capita do Brasil, apesar de possuir uma população de apenas 3.055.149 e ter um setor industrial que corresponde a apenas 4,2\% desse PIB, em simultâneo, a principal atividade econômica do DF diz respeito ao setor de serviços, correspondendo a 50,3\% do PIB.

Essa constatação demonstra que a principal fonte econômica do DF está relacionada à média geral da renda da sua população, que sustenta a dinâmica de funcionamento do setor de serviços enquanto principal fonte do PIB. Contudo, em relação à distribuição dessa renda o DF apresenta uma desigualdade entre regiões administrativas que varia entre a renda per capita mais baixa que vai até $R \$ 500,00$ e a renda per capita mais alta que se situa entre $R \$ 7.000,00$ a $R \$ 8.000,00$.

Esse indicador demonstra a profunda desigualdade socioeconômica existente no DF, principalmente quando se identifica que associado a isso, as regiões possuidoras da menor renda do PIB per capita possuem os maiores índices de desemprego e de trabalho informal. Situação agravada durante a pandemia da COVID-19, conforme demonstrado pelos dados coletados.

Nesse sentido, os dados demonstram que no contexto do primeiro ano da pandemia da COVID-19 o DF manteve o índice de desemprego anual na média de $18 \%$. Porém, nos meses de intensificação da pandemia houve um aumento do desemprego para 21,6\% em que novamente as regiões administrativas com menor renda do PIB per capita tiverem os maiores índices, assim como maiores índices em relação à diminuição da renda e de aumento do trabalho informal.

É visível a partir disso que a população dessas regiões administrativas, formadas por diferentes segmentos da classe trabalhadora, (que quando não se encontram desempregados, se inserem no mercado de trabalho de maneira predominantemente desregulamentada, informal ou temporária) é o segmento que no DF tem enfrentado as consequências mais severas do atual quadro de crise vivenciada no Brasil.

Essa constatação demonstra que o atual acirramento da "questão social" no DF está permeado pelo aprofundamento da desigualdade socioeconômica que anterior à pandemia já se demonstrava em níveis abissais.

Com isso, diante do atual quadro de piora da pandemia, a continuidade dessa pesquisa pretende buscar dados que demonstrem outros aspectos das condições de vida dessa população, como o acesso à saúde pública e à moradia. Além da intenção de se buscar o conhecimento sobre como a pobreza extrema tem se manifestado no DF, a exemplo dos atuais níveis de insegurança alimentar.

Nessa perspectiva, entende-se que conhecer essa realidade de forma aprofundada e dar visibilidade a essa situação do DF, se constitui em parte do processo de produção do conhecimento sobre a realidade brasileira que deve subsidiar ações dirigidas à superação da grave condição de vulnerabilidade enfrentada pelos segmentos mais pobres da classe trabalhadora no tempo presente.

Essa constatação aponta a importância da realização de pesquisas que envolvam reflexões sobre as possibilidades de enfrentamento da desigualdade socioeconômica no DF, a exemplo de temas acerca das políticas sociais, do desenvolvimento de medidas de proteção social e de fomento à política de emprego e renda.

\section{Referências}

Agência Senado. (2021). Recordista em desigualdade, país estuda alternativas para ajudar os mais pobres. https://www12.senado.leg.br/noticias/infomaterias/2021/03/recordista-em-desigualdade-pais-estuda-alternativas-para-ajudar-os-mais-pobres.

Almeida, L. F. R. de. (2012). Entre o nacional e neonacional-desenvolvimentismo: poder político e classes sociais no Brasil contemporâneo. Serviço Social e Sociedade. Cortez, (12), 689-710.

Almeida, S L de. (2018) Neoconservadorismo e liberalismo. In: (Org.). Gallego, S E. O ódio como política: a reinvenção da direita no Brasil. Boitempo.

Antunes, R. (2010). Adeus ao trabalho? Ensaio sobre as metamorfoses e a centralidade do mundo do trabalho. (14a ed.), Cortez.

Behring, E; Boschetti, I. (2008). Política Social: fundamentos e história. (5a ed.), Cortez Editora. 
Research, Society and Development, v. 10, n. 5, e28310514976, 2021

(CC BY 4.0) | ISSN 2525-3409 | DOI: http://dx.doi.org/10.33448/rsd-v10i5.14976

Boito Junior A. (2012) Governos Lula: a nova burguesia nacional no poder. In: Boito J A.; Galvão, A. (Orgs.) Política e classes sociais no Brasil dos anos 2000. Alameda.

Chesnais, F. (1996) A mundialização do capital. Xamã Editora.

Companhia de Planejamento do Distrito Federal. (2020). Apresentação PIB DF-DF 2018. http://www.codeplan.df.gov.br/wpcontent/uploads/2018/02/Apresentacao-PIB-DF-2018-13.11.2020.pdf.

Companhia de Planejamento do Distrito Federal. (2020a). Atlas do Distrito Federal. http://www.codeplan.df.gov.br/wp-content/uploads/2018/05/Atlas-doDistrito-Federal-2020-Cap\%C3\%ADtulo-5.pdf.

Companhia de Planejamento do Distrito Federal. (2020b). Mercado de trabalho informal: uma perspectiva comparada. http://www.codeplan.df.gov.br/wpcontent/uploads/2018/03/NT-Mercado-de-Trabalho-Informal-uma-perspectiva-comparada-do-DF.pdf.

Companhia de Planejamento do Distrito Federal. (2021). Pesquisa de Emprego e Renda. http://www.codeplan.df.gov.br/ped-pesquisa-de-emprego-edesemprego.

Companhia de Planejamento do Distrito Federal. (2021a). Boletim de conjuntura do DF. http://www.codeplan.df.gov.br/wpcontent/uploads/2018/02/Boletim_de-Conjuntura_do_DF_2\%C2\%BA_Trimestre-2020.pdf.

Iamamoto, M. V. (2010). Serviço Social em tempo de capital fetiche: capital financeiro, trabalho e questão social. (4a ed.), Cortez.

Instituto Brasileiro de Geografia e Estatística. (2020). Cidades. https://cidades.ibge.gov.br/brasil/df/brasilia/panorama.

Instituto Brasileiro de Geografia e Estatística. (2020a). https://www.ibge.gov.br/estatisticas/sociais/rendimento-despesa-e-consumo/9173-pesquisanacionalpor-amostra-de-domicilios-continua-trimestral.html?edicao $=29516 \& \mathrm{t}=$ resultados.

Konder, L. (2000). O que é dialética. Braziliense.

Kosik, K. (1976). Dialética do concreto. (2a ed.), Paz e Terra.

Marini, R M. (2005). Dialética da dependência. In: Stedile, J. P., Traspadini, R. (Orgs.). Ruy Mauro Marini: Vida e Obra. Expressão Popular.

Marx, K. (1989). O Capital - crítica da Economia Política. O processo de produção do capital. (13 ed.), Bertrand Brasil.

Minayo, M. C de S. (2012) et. al. (Org.). Pesquisa social: teoria, método e criatividade. (31a ed.), Vozes.

Mota, A. E; Rodrigues, M. (2020). Legado do Congresso da Virada em tempos de conservadorismo reacionário. Revista Katálysis, Florianópolis, 23(2). 199212 .

Netto, J. P. (2006) Capitalismo monopolista e Serviço Social. (5a ed.), Cortez.

Paulani, L. M.(2019). Bolsonaro, o ultraneoliberalismo e a crise do capital. Margem Esquerda: dossiê Governo Bolsonaro. Boitempo.

Pochmann M. (2020). Os trabalhadores na regressão neoliberal. In: Pochmann, M; Oliveira, D. A. de. A devastação do trabalho: a classe do labor na crise da pandemia. Editora Positiva.

Santos, J. S. (2012). “Questão social”: particularidades no Brasil. Cortez. 